\title{
LAS CARRETERAS Y AUTOPISTAS PROVINCIALES DE PEAJE
}

625.711 .3

por

Juan Climent Barberá

SUMARIO: I. INTRODUCCION.-II. EL REGIMEN JURIDICO ANTERIOR A LA LEY DE CARRETERAS DE 19 DE DICIEMBRE DE 1974: 1. El SISTEMA ANTES DE LA LEY 8/1972: A) El concepto de autopista. B) Clases de carreteras: a) Carreteras del Estado. b) Carreteras provinciales. c) Caminos vecinales. d) Carreteras costeadas por los particulares y por fondos mixtos. C) La concesión de carreteras. D) El peaje. E) La jurisprudencia y la doctrina del Consejo de Estado sobre la concesión de carreteras de peaje por las Provincias. F) Conclusión. 2. LA LEY 8/1972, DE 10 DE MAYO, DE CONSTRUCCIÓN, CONSERVACIÓN Y EXPLOTACIÓN DE AUTOPISTAS EN RÉGIMEN DE CONCESIÓN: A) El concepto legal de autopista. B) Ambito de la Ley de Autopistas.-III. LA REGULACION ACTUAL, CONSECUENCIA DE LA LEY DE CARRETERAS DE 1974: 1. LAS CARACTERISTICAS DE LA LEY 51/ 1974, DE 19 DE DICIEMBRE. Definiciones legales. 2. ClasifiCaCión de LAS CARRETERAS Y DISTRIBUCION DE COMPETENCIAS. 3. LAS CARRETERAS Y AUTOPISTAS PROVINCIALES: A) Concepto. B) Los tipos de carreteras provinciales por razón del peaje. C) El régimen jurídico específico de las carreteras provinciales de peaje: a) Las carreteras provinciales de peaje explotadas por sus entes titulares: a') Construcción y financiación. b') El carácter de servicio público. c') Las formas de gestión directa. d') Tarifas de peaje. b) Las carreteras provinciales de peaje explotadas por particulares: a') La concesión: a") El objeto de la concesión. b") Competencia para el otorgamiento de la 
concesión y titularidad del servicio. b') El arrendamiento. c') La gestión por empresa mixta. D) Financiación y tarifas.-IV. CONCLUSIONES.

\section{INTRODUCCION}

El tema que nos planteamos resulta interesante en el contexto de los varios aspectos que las vías públicas, en especial las interurbanas, nos ofrecen.

En torno a la vía pública urbana o interurbana se ciernen multitud de cuestiones de indudable atracción en el seno del Derecho administrativo. Hablar de una vía pública supone el tratamiento de cuestiones de tal magnitud como los de las competencias de los entes territoriales, el dominio público y el uso público; la contratación administrativa y los aspectos financieros de su construcción y explotación entre otros.

Nos centramos en el estudio de algunas de esas vías, concretamente las carreteras de competencia propia de las Diputaciones provinciales, y de entre ellas, en las de peaje. Las vías provinciales de peaje son, desde el punto de vista de la realidad fáctica actual, muy escasas, por no decir prácticamente inexistentes; desde el punto de vista de su normativa jurídica, su regulación ha alcanzado, con motivo de la Ley de Carreteras de 19 de diciembre de 1974, una nueva perspectiva que ofrece mayor claridad en su régimen jurídico.

La regulación de las carreteras y autopistas provinciales de peaje, en esta normativa, contrasta fuertemente con la situación anterior a la aplicación de aquélla. Pretendemos una rápida visión de su actual régimen jurídico que nos lleve a observar los problemas que plantea, y por ello estudiaremos en primer lugar el sistema anterior a la Ley de Carreteras para poder establecer el adecuado contraste entre la vieja y la nueva regulación, así como el proceso evolutivo sufrido al respecto, limitándonos, como consecuencia de ello, a la exposición del tratamiento jurídico-positivo del tema. 


\section{EL REGIMEN JURIDICO ANTERIOR A LA LEY DE CARRETERAS DE 19 DE DICIEMBRE DE 1974}

\section{El SISTEMA ANTES DE LA LeY $8 / 1972$}

\section{A) El concepto de autopista}

El artículo $5 .^{\circ}$ del Código de la Circulación, aprobado por Decreto de 22 de julio de 1958, define las vías públicas como todo camino utilizable, sin más limitaciones que las impuestas en dicho Código, y distingue, dentro de ellas, las interurbanas o carreteras y las urbanas o calles.

Las primeras son toda vía pública situada fuera del casco de las poblaciones, provistas de afirmado y con organización regular de su explanación y calzada. Las segundas son las comprendidas dentro de los cascos urbanos, entendiéndose por tales el conjunto de edificaciones agrupadas, sin que existan en ellas soluciones de continuidad mayores de 500 metros (1).

El citado texto reglamentario, en el dicho artículo $5 .^{\circ}$, define la travesía como calle o vía urbana que queda comprendida dentro del desarrollo de una carretera.

Pista queda definida como toda vía pública destinada a la circulación de vehículos de determinadas características.

Ni la Ley de Carreteras de 4 de mayo de 1877 ni la Ley de Carreteras en régimen de concesión (2) definen qué es una carretera y menos aún qué es una autopista. Tampoco se precisan estos extremos en el Decreto (3) en el que se establecen determinadas autopistas nacionales de peaje.

La conceptuación de vías públicas dada por el Código de la Circulación se deduce, a efectos interpretativos, al propio texto del Código, ya que en su artículo $2 .^{\circ}$ se establece que las personas, vehículos, vías públicas y partes de éstas por las que circulan aquéllos se entenderán definidos a los efectos del presente Código como lo hemos enunciado anteriormente.

(1) Sobre criterios de delimitación de vías urbanas, vid. Escribano Collado, P., Las vias urbanas, Madrid, 1973, Montecorvo, págs. 28 y ss.

(2) Ley $55 / 1960$, de 22 de diciembre.

(3) Decreto $3.255 / 1965$, de 28 de octubre. 
Sin embargo, dada la omisión que en normas más específicas sobre la materia podemos apreciar, cabría admitir, aunque fuera como hipótesis de trabajo, la conceptuación de carretera frente a la de calle antes citada.

Más problemático resulta calificar el contenido del término autopista, nuevo, como decíamos, en nuestra vetusta legislación de carreteras.

Tomando la conceptuación de pista que da el Código de la Circulación -que entiende por tal toda vía pública destinada a la circulación de vehículos de determinadas características- y la composición de la palabra autopista, podría entenderse por tal la vía pública destinada a la circulación de vehículos automóviles.

Sin embargo, el apunte de definición no es completo ni congruente con la realidad material en su totalidad, ya que, de hecho, autopista es una vía destinada a la circulación de vehículos automóviles cuya característica fáctica es el carecer de cruces de cualquier tipo y poseer separación total entre las distintas direcciones de circulación.

Tal concepción carece de refrendo legal; sin embargo, el término autopista, paradójicamente, aparece recogido en textos legales y reglamentarios, antes de su precisión en la modificación del Código de la Circulación realizada en 1969 (4).

Para obtener el contenido que en Derecho se ha de entender atribuido a este término no cabe sino recurrir a los pliegos de condiciones de las autopistas objeto de concesión, ya que en ellos se recogen las características de estas vías de circulación.

Ello, sin embargo, entraña el grave inconveniente de que tan sólo será válida tal conceptuación para cada autopista conocida y según sus pliegos de condiciones, pero ni vincula a la Administración a la hora de redactar nuevos proyectos ni supone óbice a una nueva y distinta calificación de tal término susceptible de operarse con cada nuevo proyecto de autopista.

(4) El Decreto $1.277 / 1969$, de 26 de junio, modifica el artículo 5. del Código de la Circulación, al que se añade, entre otros, un apartado «U» que define la autopista como a... vía especialmente concebida y construida para la circulación de automóviles a la que no tienen acceso las fincas colindantes y que: a) Salvo en pun. tos singulares con carácter temporal, consta de distintas calzadas para cada sen. tido de circulación, separadas entre sí por una franja de terreno no destinada a la circulación, denominada mediana, o en casos excepcionales por otros medios; b) No cruza a nivel ninguna otra via ni línea de ferrocarril o de tranvía ni es cruzada por senda o servidumbre de paso alguna, y c) Está especialmente señalizada como autopistax. 
Con ello llegamos a un punto en el que es preciso admitir la inexistencia de un concepto jurídico claro, concluyente y general para determinar lo que sea autopista, sin que ello suponga la imposibilidad de determinar en un momento dado y un caso concreto - por ejemplo, una concesión existente- qué sea lo que se entiende por autopista con anterioridad a 1969.

\section{B) Clases de carreteras}

Por razón de los organismos encargados de su construcción, la Ley de 4 de mayo de 1877 clasificó las carreteras en cinco grupos: costeadas por el Estado, por las Provincias, por los Municipios, por los particulares y por fondos mixtos; las del Estado se clasificaban, según su importancia, en: de primero, de segundo y de tercer orden.

La Ley de 11 de abril de 1939 divide las carreteras en nacionales, comarcales y locales, en sustitución de la clasificación anterior. Las nacionales enlazan Madrid con las capitales de Provincia, éstas entre sí y con las costas y fronteras.

En las comarcales figura la red de segundo orden, que sirve zonas importantes para la agricultura, industria y comercio. Se consideran locales las restantes carreteras y los caminos vecinales (5).

\section{a) Carreteras del Estado}

Según la Ley de 1877, todas las carreteras que hayan de construirse y conservarse por cuenta del Estado han de estar incluidas, para evitar su construcción desarticulada, en un plan general que será objeto de una ley y no podrá ser modificado sino por otras leyes y en la forma que establece (expediente previo con su informe del Ayuntamiento, Diputación, ingenieros, etc.). Aprobar el proyecto, clasificar la carretera y acordar su ejecución corresponde al Ministerio de Fomento, cuyas funciones asumió el de Obras Públicas.

Las obras de conservación y reparación corren también a cargo

(5) Acerca de las clases de carreteras y caminos, puede verse Peinado Pérez, Lucas: «Vías provinciales y otros caminos. Coordinación entre las diversas de. nominaciones oficiales", en I Jornadas Nacionales de Estudios sobre Vias Provinciales, IEAL, Madrid, 1969, págs. 214 y ss. 
del Estado y habrán de tener consignación en los Presupuestos; podrán efectuarse por administración o por contrata.

La Ley de Bases de 1960 vino a llenar el hueco que dejó el aplazamiento por diez años de la puesta en marcha del Plan de modernización de 1950. El nuevo Plan general se desarrollará en el plazo de dieciséis años, agrupados en cuatrienios y en coordinación perfecta con los demás Planes de desarrollo económico del país. A tal fin, el Gobierno deberá someter a la aprobación de las Cortes el plan de actuación en cada cuatrienio.

\section{b) Carreteras provinciales}

La Ley de 1877 consideró como tales todas las que, no incluidas en el Plan general del Estado, debían serlo en el que habían de formar las Diputaciones provinciales para construirlas, conservarlas y repararlas con cargo a sus presupuestos.

La aprobación del Plan mencionado compete al Ministerio de Obras Públicas, y la de cada proyecto en concreto, a la Diputación, cuando la obra no afecte al dominio público, y al Gobernador, cuando haya de ocuparse parte de este dominio.

La Ley de 1939 pone a cargo del Estado, bajo la denominación de carreteras comarcales, la construcción de las que figuran en el Plan aprobado por ella, en relación con las Provinciàs liberadas que señala.

La Ley de Régimen local de 1955 menciona entre los servicios de la competencia provincial la construcción y conservación de caminos y vías locales y comarcales (6).

\section{c) Caminos vecinales}

La Ley de 1877 puso a cargo de los Municipios las carreteras que, no hallándose comprendidas en los Planes del Estado ni en los de las Provincias, acordaren construir los Ayuntamientos. Pero imposibilitados éstos en su mayoría para construirlos se dictó la Ley de 29 de junio de 1911, en la que se facultó al Estado para auxiliarlos con anticipos y subvenciones.

(6) Artículos 285 a 291 del texto articulado y refundido aprobado por Decreto de 29 de junio de 1955. 
Fue el Estatuto provincial de 1925 el que obligó a las Diputaciones provinciales a dotar de caminos vecinales sus respectivos territorios, de forma que tuvieran comunicación todos los núcleos poblados que excedieran de 75 habitantes. Así también lo dispone la Ley de Régimen local (7).

A partir del citado Estatuto, la construcción y conservación de los caminos vecinales corrió a cargo de las Diputaciones, pero subvencionándolas el Estado durante un período diez años -elevado después a veinticinco (8)—. A dicho fin, las Diputaciones en Pleno aprobarían el Plan provincial de caminos vecinales, que deberían elevar al Ministerio de Obras Públicas, entendiéndose aprobado definitivamente si no se dictaba acuerdo sobre él en el término de sesenta días.

Por último, la Ley de 1939 ha puesto a cargo del Estado, con la denominación de carreteras locales, la construcción de los referidos caminos vecinales que aparezcan incluidos en el Plan que aprueba; pero esta nueva clasificación de nacionales, comarcales y locales no presupone cambio en la entidad encargada de su conservación.

\section{d) Carreteras costeadas por los particulares y por fondos mixtos}

Según la Ley de 1877, las carreteras podrán ser construidas por particulares en virtud de concesión administrativa y sin subvención alguna, y por fondos mixtos mediante la unión de recursos, ya del Estado con las Diputaciones, ya de éstas con los Ayuntamientos, ya de las entidades públicas con los particulares.

La Ley de 1960 aprobó las normas para la construcción, conservación y explotación de carreteras por los particulares mediante el sistema de concesión de peaje. Su Exposición de Motivos afirma que el Estado, aun considerando la construcción de carreteras de interés general, se ve forzado a aplazar su ejecución por la exigencia de la inversión de créditos disponibles en obras más urgentes, necesitando para ello de la iniciativa privada.

Consecuentemente, la Ley autoriza al Gobierno para conceder por tiempo determinado, no superior a noventa y nueve años, a particulares, sociedades, corporaciones públicas, organismos autónomos o empresas nacionales, la construcción, conservación y explotación de carreteras e instalaciones complementarias.

(7) Artículo 251.

(8) Real Decreto-ley de 12 de diciembre de 1926. 
La concesión se hará por Decreto, a propuesta del Ministro de Obras Públicas. Cuando las circunstancias lo aconsejen, el Gobierno podrá acordar la participación del Estado en la cuantía que en cada caso se decida.

En los casos en que el Estado no participe o esta participación sea minoritaria podrá designar un Delegado del Ministerio con las facultades que se señalen en la concesión.

Estas concesiones, otorgadas por concurso, podrán hacerse: a) con carácter oneroso; b) gratuitamente, y c) subvencionadas por el Estado. En los tres casos podrá otorgarse, además, al concesionario la exclusividad de los servicios e instalaciones inherentes a la misma, debiendo en todo caso ser aprobadas sus tarifas.

Asimismo podrá concederse el derecho de peaje con tarifas aprobadas y otros beneficios, como son la calificación del preferente interés económico-social, bonificaciones fiscales y la declaración de utilidad pública a los efectos de expropiación forzosa.

En ejecución de la Ley de 1960 se determinaron las «autopistas nacionales de peaje que serán objeto de concesión» (9). Ya al amparo de la Ley de 26 de febrero de 1953 (10) se construyó el túnel de Guadarrama; posteriormente se concedieron las autopistas Barcelona-La Junquera y Mongat-Mataró (11), Bilbao-Behobia (12), Villalba-Villacastín (13) y Sevilla-Cádiz (14).

\section{C) La concesión de carreteras}

Respecto de las carreteras del Estado, no existe problema a la hora de determinar la posibilidad de su concesión. La Ley de Carreteras de 1877 admite la posibilidad de ésta y establece el procedimiento de concesión, remitiéndose a lo establecido en la Ley de Obras Públicas (15). En todo caso, la Ley de Carreteras en régimen de concesión (16) establece y regula, junto con sus disposiciones complementarias, el sistema de concesión de carreteras del Estado.

(9) Por Decreto de 28 de octubre de 1965.

(10) Derogada por la Ley de Bases de 22 de diciembre de 1960.

(11) Decreto-ley de 22 de julio de 1966.

(12) Decreto-ley de 28 de junio de 1967.

(13) Decreto-ley de 27 de septiembre de 1967.

(14) Decreto-ley de 13 de febrero de 1969.

(15) De 13 de abril de 1877.

(16) Ley 55/1960, de 22 de diciembre. 
La posibilidad de concesión de carreteras provinciales, y, por tanto, la de autopistas, podía centrarse en torno a tres regulaciones legales. Hay que determinar si es aplicable al supuesto la Ley de Carreteras en régimen de concesión de 1960 antes citada (17); hay que examinar la posibilidad de aplicación de la normativa legal de carácter local relativa a la concesión, y por último hay que estudiar la posible aplicación de la legislación de carreteras en conexión con la general de obras públicas de 1877.

En relación con el primer punto, la Ley de 1960 citada no precisa si las carreteras a conceder serán exclusivamente del Estado o si se podrá aplicar su regulación y contenido a las de carácter provincial o municipal. Sin embargo, las disposiciones posteriores, en especial el Decreto de 28 de octubre de 1965 (18) que determina las autopistas nacionales de peaje, interpretan la citada norma como aplicable a las carreteras del Estado. Además de ello, la doctrina jurisprudencial del Tribunal Supremo, en sentencia de 19 de mayo de 1965, establece la inaplicabilidad de esta Ley a las carreteras provinciales.

Respecto a la segunda normativa a examinar, es de señalar que la Ley de Régimen local (19) establece que podrán ser objeto de concesión a individuos o entidades particulares los diversos servicios de la Corporación que se acuerde establecer o mantener. La concesión en materia de Régimen local aparece en la Ley del mismo nombre y en el Reglamento de Servicios de las Corporaciones locales (20) como una forma de gestión indirecta de servicios. Aun cuando esta concesión pueda comprender - como reconoce el citado Reglamento de Servicios (21) - la construcción de una obra o instalación, se trata de una concesión de servicio no aplicable a las carreteras provinciales por su especial calificación jurídica y por el régimen de la Ley de Carreteras de 1877.

Las carreteras provinciales están calificadas por la Ley de Régimen local (22) como bienes de dominio público, y dentro de esta categoría, como bienes de uso público frente a la otra categoría

(17) Santos Briz, J., «Las autopistas. Su régimen en el ordenamiento español", en Revista de Derecho de la Circulación, núm. 2, 1970, págs. 105 y ss., al estudiar las autopistas en el contexto de estas normas refiere su titularidad al Estado.

(18) Decreto $3.255 / 1965$.

(19) Artículo 160.

(20). Aprobado por Decreto de 17 de junio de 1955.

(21) Artículo 14, 2, a).

(22) Artículos 281 y 282. 
de bienes de servicio público; en idéntico sentido se expresa el Reglamento de Bienes de los Entes locales (23). Por último, el Código civil (24) menciona entre los bienes de dominio público destinados al uso público a los caminos, aunque, como veremos, la Ley de Régimen local los configura también como servicios en su artículo 243.

Desechadas las anteriores regulaciones legales a tenor de lo expuesto, queda por último el examen de la vetusta legislación de obras públicas y de carreteras de 1877 , que establece la posibilidad de construcción y explotación de carreteras por particulares (25), y ello siguiendo lo ya establecido en la Ley de Obras públicas sobre el tema (26), señalándose la fórmula de tramitación de estos supuestos, tanto en caso de carreteras del Estado como en las locales (27), especificando las competencias para la concesión según el tipo de carreteras y la presencia o no de subvención (28).

(23) Artículo 3. , Reglamento aprobado por Decreto de 27 de mayo de 1955.

(24) Artículo 339, apartado $10^{\circ}$.

(25) El artículo 46 de la Ley de Carreteras de 1877 establece: aLas carreteras de servicio público que constituyen el objeto de esta Ley podrán ser construidas y explotadas por particulares o compañias mediante concesiones para reintegro de los capitales invertidos y sin subvención alguna por parte del Estado, Provincias ni Ayuntamientos, al tenor de lo prescrito en el artículo 53 de la Ley General de Obras públicas».

(26) El artículo 53 dice que ulos particulares y compañías podrán también construir y explotar obras públicas destinadas al uso general y los demás que se enumeran en el artículo $70^{\circ}$ de esta Ley mediante concesiones que al efecto se otorguen». Entre las obras que señala el artículo $70^{\circ}$ mencionado se encuentran las carreteras.

(27) El artículo 47 de la Ley de Carreteras prescribe: «Si se tratase de carreteras comprendidas en el Plan general de las del Estado, a la concesión deberá preceder el correspondiente proyecto, que el peticionario deberá firmar, previa la autorización que prescribe el artículo 57 de la Ley General de Obras públicas. La aprobación del proyecto se hará con arreglo a lo previsto en el artículo 12 de la presente Ley, y la concesión se otorgará, en su caso, por el Ministerio de Fomento (hoy de Obras Públicas), en virtud del Real Decreto acordado en Consejo de Ministros y en los términos que marcan los artículos 54 y 55 de la expresada Ley General.

Trámites análogos se seguirán si la carretera de que se trate se hallase comprendida en los Planes de las Provincias o de los Municipios, según se determina en los Reglamentos.

La concesión del dominio público se hará por el Gobierno o sus delegados».

(28) El artículo 54 de la Ley de Obras públicas establece: «Dichas concesiones, siempre que no se pidiere subvención ni ocupación constante del dominio público, ni se destruyan con ellas los planes a que se refieren los artículo 20,34 y 44, se otorgarán, respectivamente, por el Ayuntamiento a cuyo cargo correspondan las obras. Las concesiones de obras para las cuales no se pida subvención, pero que destruyan los planes de obras a cargo del Estado a que se refiere el artículo 20, no podrán ser otorgadas sino por medio de una ley. En el mismo caso, las que destruyan los planes de obras provinciales o municipales citados en los artículos 24 y 44 no podrán ser otorgadas sino por medio de Reales Decretos expedidos por el Ministerio de Fomentos. 


\section{D) El peaje}

Sin entrar en los problemas de índole tributaria que supondrían el determinar el carácter fiscal del comúnmente llamado peaje, señalaremos que se trata en un sentido amplio de la aportación económica que realizan los usuarios de una vía pública como contraprestación del uso que de la misma hacen y que por lo general se caracteriza por la reiteración de la misma cada vez que se hace uso de la misma (29).

Desde el punto de vista de las disposiciones a manejar es de señalar que la Ley de Carreteras en régimen de concesión (30) califica al peaje, que en ella se establece, como tasa. El peaje se diferencia esencialmente de otras tasas de análoga finalidad y objeto en que se percibe cada vez que se usa determinada vía de circulación, mientras que los otros tipos, por ejemplo las llamadas tasas de rodaje, se perciben de una sola vez, por períodos de tiempo determinados y con independencia del mayor o menor uso que se haga de la vía pública.

Respecto de las carreteras estatales en régimen de concesión lo permite la citada Ley de Carreteras de 1877 (31), y lo establecía concretamente la mencionada Ley de 1960 respecto de las carreteras en régimen de concesión (32).

Respecto de las carreteras provinciales, la Ley de Carreteras de 1877 establecía una regulación análoga (33). Con ello parece que la posibilidad de que las Diputaciones impongan tasas de peaje es factible desde el punto de vista legal, aun cuando sea preciso que exista una aprobación superior. En este sentido abunda la doctrina del Consejo de Estado (34).

Si la autopista, como hemos dicho, es un tipo especial de ca-

(29) Cf. ARIÑo ORtiz, G., Las tarifas de los servicios públicos, Instituto García Oviedo Sevilla, 1976. pág. 16.

(30) Ley 55/1960, de 22 de diciembre.

(31) Artículo 20. «El Gobierno podrá establecer impuestos o arbitrios por el uso de las carreteras del Estadon.

(32) Artículo 5. «Las concesiones, cuando así se acuerde en el correspondiente Decreto, darán derecho a percibir de los usuarios una tasa de peaje cuyas tarifas serán previamente establecidas por el Gobierno».

(33) Artículo 35. "Las Diputaciones provinciales podrán establecer, con la aprobación superior, impuestos o arbitrios por el uso de las carreteras de su cargo, destinando los productos a la conservación o reparación de estas líneas y al reintegro de los fondos en ellas invertidos".

(34) Dictamen de 19 de febrero de 1973 (expediente núm. 29.343). 
rretera sin una calificación legal de tipo general hasta 1969, será posible que las Diputaciones provinciales puedan realizarlas si así se prevé en los planes provinciales de carreteras, siempre que se construyan en vías de su competencia.

Si las Diputaciones, como establece la Ley de Carreteras, pueden establecer impuestos y arbitrios, con la aprobación superior, por el uso de las que estén a su cargo, podrán existir carreteras provinciales de peaje. Dado el carácter primordial de tipo especial de carretera que a la autopista se le puede atribuir y el hecho de que si bien no se regula legalmente la construcción de autopistas por parte de las Diputaciones, tampoco se prohibe la misma, es necesario concluir que cabría la construcción por las Diputaciones de autopistas, y, por su carácter de carreteras, aunque especiales, cabría, acogiéndose a la Ley de Carreteras de 1877, establecer tasas por su uso.

\section{E) La jurisprudencia y la doctrina del Consejo de Estado sobre la concesión de carreteras de peaje por las Provincias}

La concesión de carreteras de peaje de carácter provincial se ha tratado por la jurisprudencia y el Consejo de Estado que vienen a coincidir en la línea de planteamiento expuesta en torno al régimen jurídico previo a la Ley de Carreteras de 1974 y a la de autopistas en régimen de concesión de 1972.

La sentencia de 19 de mayo de 1965 (35) resuelve un supuesto

(35) El Tribunal Supremo, en sentencia de 19 de mayo de 1965 (Sala 3.॰), conoce el siguiente supuesto. La Jefatura de Obras Públicas de Barcelona presentó a la Dirección ministerial un plan de caminos de enlace con la construcción de autopista y cobro de peaje a los usuarios. Aprobado técnicamente el plan, la Dirección General resolvió que la construcción de la autopista aludida, con túnel en el Tibidabo, se ajusta a las prescripciones legales sobre carreteras en régimen de concesión que pretenda establecer derechos de peaje, y si no se pretende dicho cobro, la Diputación de Barcelona deberá presentar a la Dirección el proyecto correspondiente con arreglo a la Ley General de Carreteras de 4 de mayo de 1877.

Este acuerdo fue recurrido en alzada ante el Ministerio, el cual lo resolvió en el sentido de estimar en parte el recurso anulando la Resolución impugnada en cuanto a la aplicación de la Ley de 22 de diciembre de 1960 y confirmándola en cuanto a la necesidad de cumplir la Ley de Carreteras de 1877.

El Ministerio de Obras Públicas desestima el recurso de reposición.

Al presente supuesto, el Tribunal Supremo aplica las siguientes consideraciones juridicas:

- Que no puede incluirse la autopista proyectada por la Diputación demandante, dada su característica de moderna y grande vía de comunicación, incluso con túnel bajo el Tibidabo, en la acepción genérica de camino vecinal. Impide hacerlo 
entre una Diputación provincial que pretende aplicar este régimen de concesión de autopista provincial y la Dirección General de Carreteras. De sus considerandos se pueden destacar varios puntos de interés.

En primer lugar, que cabe la realización de una autopista de carácter provincial, y que ello es subsumible en la regulación de la Ley de Obras públicas de 1877 y de carreteras del mismo año, por cuanto la sentencia declara aplicable la Ley de Carreteras y ésta se remite a la Ley de Obras públicas, excluyéndose expresamente todo intento de aplicar la legislación de caminos vecinales.

En segundo lugar se declara aplicable a las carreteras del Estado la Ley de 1960, e inaplicable a las provinciales.

En tercer lugar se confirma que la intervención del Estado que establece la Ley de Carreteras - como hemos visto- prevalece frente a cualquier pretensión de exclusiva competencia provincial basada en las prescripciones de la Ley de Régimen local.

Asimismo, el Consejo de Estado, en dictamen de 14 de febre-

así la Ley de 29 de junio de 1911, su Reglamento y el Decreto de 12 de diciembre de 1926, según la cual ordenación aquéllos han de ser construidos en máximas condiciones de economía y ajustados a las más elementales exigencias del tráfico, lo que pugna y esencialmente difiere de lo que ahora proyecta.

- Que, eliminado el concepto aludido, sólo es operante, para la tramitación y aprobación, en su caso, la normativa general de la Ley de Carreteras de 4 de mayo de 1877, en la que se incluyen las costeadas por las Provincias, porque tal acepción es la que encaja en la naturaleza de lo que va a construirse, sin que la intervención estatal se pueda eludir, pues, si bien es cierto que la obra queda dentro del ámbito de la competencia que se atribuye a las Diputaciones por los artículos 242 y 243 de la Ley de Régimen local, no puede olvidarse que la misma se establece por los propios preceptos, "con sujeción a las leyes generales", es decir, que tal competencia no puede nunca ser excluyente de las facultades privativas, en la materia, del Ministerio de Obras Públicas, como elemento coordinador de los intereses generales.

- Que tampoco es admisible desarticular el proyecto de autos de la coordinación que se exige en la Ley de 3 de diciembre de 1963, por la que se aprobó el Plan Comarcal de Ordenación Urbana de Barcelona, pues, por el artículo $5 .^{\circ}$ de su Reglamento, el desarrollo y ejecución del Plan y de cuanto suponga formulación de sus aspectos parciales, y la obra citada lo es, será competencia de los órganos que allí se mencionan, para armonizar todos los matices, incluso el urbanístico.

Por tanto, está bien indicada la salvedad y prevención que se hace en la Orden recurrida en cuanto a la necesidad de cumplir la Ley de 1877, pero cohonestando su aplicabilidad con lo específicamente definido en la de 1963.

- Que normas reguladoras de las concesiones de vías en régimen de peaje, fundamentalmente contenidas en la Ley de 22 de diciembre de 1960, no son operantes más que para las que se otorguen por el Estado, el cual sólo lo hace en las de interés general, o porque ellas son las constitutivas de servicios estatales, robusteciéndose éste ante el hecho posible de percepción de impuestos o arbitrios por el uso de carreteras a cargo de las Diputaciones, en virtud del artículo 35 de la Ley ya aludida de 1877, pero en los límites y extensión que el precepto señala. 
ro de 1963 (36), establece una interpretación de la situación legislativa de la concesión de carreteras provinciales de peaje muy interesante, por cuanto gira en torno a la delimitación de lo que sea carretera provincial, el régimen jurídico aplicable y las competencias concesionales y de imposición de tasas de peaje.

La doctrina sentada por el Consejo de Estado puede resumirse en los siguientes puntos:

En primer lugar, el carácter de carretera provincial se deriva del interés territorial de la vía y de su inclusión en el Plan de carreteras provinciales, así como de la no inclusión en el Plan general del Estado.

En segundo lugar, el establecimiento de tasas de peaje en carreteras provinciales puede hacerse por la Diputación Provincial, previa autorización del Gobierno, sin que la Corporación asuma la posición de concesionario del Estado.

(36) El Consejo de Estado evacua consulta respecto a la definición legal de carreteras en Dictamen de 14 de febrero de 1963 (expediente núm. 29.343) en los siguientes términos:

No hay una clara calificación de las carreteras provinciales que, según criterios positivos, las diferencie de las del Estado. En el artículo 25 de la Ley de Carreteras de 1877 es el factor más decisivo el puramente negativo de que no se hallen incluidas en el Plan general del Estado, completado con un factor positivo, escasamente definitorio, cual es el que deban de ser incluidas en los Planes que hayan de formar las Diputaciones provinciales.

Sin embargo, podría intuirse el concepto legal procediendo inductivamente y dando valor a este respecto al artículo 56 del Decreto de 6 de julio de 1877, a cuyo tenor son de cargo de la Provincia los caminos de sus respectivos territorios que sean de interés meramente provincial. Si no se da valor absoluto, como el Consejo de Estado cree que no debe darse, al adverbio "meramente», resulta claro y evidente el primordialisímo interés «meramente provincial de la autopista de que se trata, y, en consecuencia, puede deducirse la calificación de la carretera como provincial.

Respecto a las carreteras provinciales de peaje, se dice en el mismo dictamen:

Es cierto que la construcción y explotación de carreteras en régimen de peaje no tiene más regulación general y sistemática que la de la Ley de 22 de diciembre de 1960 , pero es evidente que la Ley se está refiriendo a las carreteras del Estado y regula concesiones del Estado, y que el Estado sólo puede conceder obras y servicios estatales, pero no provinciales, pues no sería lógico, ni legalmente congruente con el sistema de la Ley de Carreteras y la de Obras Públicas, que si la Diputación trata de establecer tasas de peaje por el uso de una carretera provincial tenga que adoptar para ello la posición jurídica de concesionario del Estado.

Robustece esta conclusión el hecho de que la percepción de impuestos o arbitrios por el uso de carreteras de cargo de las Diputaciones está prevista en la legislación de carreteras. En consecuencia, los argumentos que pudieran esgrimirse en base a que la Ley de 1960 tiene una específica fundamentación en que, mediante el establecimiento de derechos de peaje, se imponen arbitrios y se limita el uso público, se desvanecen si se tiene en cuenta que por la vía del artículo 35 de la Ley de 1877 es el Gobierno, a través de Decreto acordado en Consejo de Ministros, el que está facultado para autorizar la percepción de derechos de peaje por el uso de carreteras de servicio público. 
Por último, en esta materia no es aplicable la Ley de Carreteras en régimen de concesión de 1960, sino la legislación de 1877.

\section{F) Conclusión}

La competencia para la construcción de una carretera viene directamente relacionada con la inclusión de ésta en un determinado Plan. Es decir, una carretera será estatal cuando se halle incluida en el Plan general de carreteras del Estado, y provincial, cuando no esté incluida en los Planes del Estado y sí en un Plan provincial de carreteras, por lo que el carácter de carretera o autopista, de un lado, y la competencia provincial o estatal, de otro, viene, en definitiva, íntimamente ligado a lo previsto en los Planes de carreteras.

En suma, podemos señalar que no cabe la aplicación de lo establecido por la Ley de Carreteras en régimen de concesión de 1960 a la concesión de carreteras provinciales. Tampoco la concesión regulada en el Reglamento de Servicios de las Corporaciones locales. La única legislación aplicable sería la general de carreteras y la más general de obras públicas, ambas caracterizadas por su antigüedad.

Si aplicáramos esta última regulación nos encontraríamos con varios supuestos a considerar. En primer lugar, a tenor de la mis. ma, sí cabía la concesión a particulares de carreteras provinciales, como se deduce de los artículos 46 y 47 de la Ley de Carreteras y el 54 de la Ley de Obras públicas.

Si se trata de una carretera provincial en que se pretende conceder, se han de seguir los trámites que se establecen para la concesión de las estatales en la regulación de 1877, todo ello analógicamente. Si dicha concesión no destruye los Planes de obras provinciales, ni se pide subvención ni ocupación del dominio público, se regirá por lo establecido en el capítulo VI de la Ley de Obras públicas (37) y por la Ley de Carreteras de 1877 en lo referente a su tramitación.

Si la Diputación auxilia la ejecución de carreteras construidas por particulares conforme permitía el artículo 54 de la Ley de Carreteras de 1877, serán aplicables a la concesión las prescripciones

(37) De 13 de abril de 1877, artículos 53 y siguientes. 
establecidas en el capítulo VII de la Ley general de Obras públicas, tal como establecía el artículo 55 de la Ley de Carreteras de 1877.

En todo caso, no hay que olvidar que el párrafo final del artículo 47 de la Ley de Carreteras de 1877 establece que la concesión del dominio público se hará por el Gobierno o sus delegados, a cuyos efectos se habría de tener en cuenta lo establecido en el capítulo VIII de la Ley de Obras públicas referente a las concesiones de dominio público (38).

Cabe señalar, además, que resulta irrelevante que el objeto de la concesión sean autopistas o carreteras provinciales de peaje; junto a ello se ha de precisar que genéricamente cabía, en aplicación de la legislación de carreteras y de obras públicas de 1877, la concesión de carreteras provinciales. El régimen de concesión en este punto era el establecido en los citados artículos y concordantes de las mencionadas leyes.

En suma, teniendo en cuenta la legislación estudiada en puntos anteriores, y de conformidad con lo establecido por la jurisprudencia y la doctrina del Consejo de Estado, podemos resumir en los siguientes puntos el estado de la cuestión en el período anterior a la Ley de 1972.

1. Autopista no es, a efectos jurídicos, otra cosa que un tipo especial de carretera, y su régimen jurídico es, a efectos generales, el mismo que el de las carreteras.

2. Cabe, por tanto, la existencia de autopistas de carácter provincial en cuanto que las Diputaciones tengan competencia sobre determinada carretera que se construya con este carácter.

3. El carácter provincial de una carretera se deriva del interés territorial de la vía y de su inclusión en el Plan de carreteras provinciales, así como de la no inclusión en el Plan general del Estado.

4. ${ }^{\circ}$ El régimen legal que establece la Ley de 22 de diciembre de 1960 , de carreteras en régimen de concesión, se circunscribe al ámbito estatal, no siendo aplicable a la Provincia su contenido.

5. La normativa aplicable se centraba, como apuntan la sentencia y dictamen citados, sobre la vieja legislación de carreteras y de obras públicas.

6. A tenor de dicha legislación resultaba posible el establecimiento de peaje en las carreteras provinciales, si bien se tenía que ajustar este establecimiento a la aprobación estatal.

(38) Artículos 94 y siguientes. 
2. La Ley 8/1972, DE 10 DE Mayo, DE CONSTRUCCIÓN, CONSERVACIÓN Y EXPLOTACIÓN DE AUTOPISTAS EN RÉGIMEN DE CONCESIÓN

\section{A) El concepto legal de autopista}

La Ley 8/1972, que regula la construcción, conservación y explotación de autopistas en régimen de concesión y que denominaremos abreviadamente Ley de Autopistas, viene a resolver por vía legislativa uno de los problemas que se planteaban en el sistema anterior que hemos descrito y que se centra en la delimitación conceptual de las autopistas.

La Ley de Autopistas contiene una definición legal de autopista (39) que salva el problema de categorización jurídico-formal del término, que, dadas las múltiples referencias de que era objeto en la legislación y actuaciones previas a esta Ley, propiciaba - al no estar formalmente fijado hasta la modificación del Código de la Circulación - una consideración variable y deslizante de su contenido.

La conceptuación legal de lo que sea y a lo que responda el término autopista es consecuencia de una necesidad apreciada en la carencia de aquélla en la legislación anterior. La precisión del término afirma la aplicatividad de las regulaciones referidas a este in genere y permite una adecuada utilización de las fórmulas normativas que se van precisando en torno al mismo.

Conviene señalar que el contenido que la configuración jurídicoformal que la Ley atribuye al término autopista se ajusta en gran manera al contenido real y usual de la expresión y además permite, por su similitud, enraizarlo en cierto modo con las consideraciones sobre la delimitación conceptual de autopista que se han planteado anteriormente dentro del conjunto normativo previo a esta regulación.

(39) Artículo 1., apartado 2.0: «Autopista es la vía especialmente concebida, construida y señalizada como tal para la circulación de automóviles y que se caracteriza por las siguientes circunstancias: a) No tienen acceso a la misma las propiedades colindantes. b) No cruza a nivel ninguna otra senda, vía, línea de ferrocarril o de tranvía ni es cruzada por senda o servidumbre de paso alguno; y c) Consta de distintas calzadas para cada sentido de circulación, separadas entre sí, salvo en puntos singulares o con carácter temporal, por una franja de terreno destinada a la circulación, denominada mediana, o en casos excepcionales por otros mediosn. Recoge sensiblemente la definición reglamentaria de la modificación de 1969 del Código de la Circulación citada (vid. nota 4). 


\section{B) Ambito de la Ley de Autopistas}

Esta Ley soluciona sólo parcialmente el problema de la delimitación de autopista y deja pendiente de regulación el de la concesión de éstas por las Diputaciones provinciales. La Ley de Autopistas resulta, de su propio contexto, aplicable exclusivamente al Estado, de forma parecida a lo que ocurría con la Ley de Carreteras en régimen de concesión (40).

La Ley de Autopistas tiene por objeto la regulación de las concesiones administrativas de construcción, conservación y explotación de autopistas (41), y la propia Ley establece que el servicio objeto de la concesión constituye una actividad propia del Estado que el concesionario gestiona en su nombre y temporalmente bajo la inspección y vigilancia de la Administración concedente (42). La Ley de Autopistas es, pues, específicamente aplicable a la Administración del Estado (43), y el estudio de la regulación concreta de la Ley no hace sino confirmar lo establecido al principio de la misma, y que hemos expuesto, en cuanto las facultades de otorgamiento, las potestades de la Administración concedente y el establecimiento de una delegación del Gobierno en la concesionaria, abundan en la referencia exclusiva de esta normativa a la Administración estatal (44).

Este planteamiento supone la inaplicabilidad de la Ley de Autopistas en bloque a la Administración local (45), y dentro de ella, en lo que nos interesa, a la provincial, por lo que, como hemos dicho, resuelve el problema de delimitación conceptual del término autopista parcialmente, en cuanto sólo será aplicable a las autopistas del Estado - al menos formalmente-, si bien su caracterización se formula abstracción hecha del ente titular de dicha vía.

(40) Ley 55/1960, de 22 de diciembre.

(41) Ley $8 / 1972$, artículo $10^{\circ}$, apartado $1 .^{\circ}$.

(42) Artículo 3.․

(43) Gomez-Ferrer Morant, Rafael, aEn torno a la Ley de Autopistas de peaje», en Revista de Administración Pública, núm. 68, 1972, págs. 325 y ss., refiere al Estado el ámbito de aplicación de esta Ley.

(44) Así, por ejemplo, en los artículos $4 .^{\circ}, 6 .^{\circ}, 7 .^{\circ}, 23,24$ y 25 , entre otros de la Ley, las referencias a la Administración concedente vienen fijadas en órganos de la Administración del Estado.

(45) En el sentido de su aplicación, sólo a la Administración del Estado, vid. RodrfGuez CARrera, J., «Las sociedades concesionarias de autopistas», en Praetor, número 86,1975 , págs. 270 y ss. 
La Ley de Autopistas supone un avance parcial sobre la situación anterior, que, en lo que a autopistas provinciales se refiere, puede quedar en los términos expuestos, porque, declarada la inaplicabilidad de la Ley de Carreteras en régimen de concesión y de esta de Autopistas que la modifica sustancialmente, seguiremos, hasta la nueva Ley de Carreteras de 1974, con la vigencia del vetusto cúmulo legislativo antes expuesto respecto de la regulación de las autopistas y carreteras provinciales de peaje.

\section{LA REGULACION ACTUAL, CONSECUENCIA DE LA LEY DE CARRETERAS DE 1974}

\section{Las CARACTERfSTicas DE LA Ley 51/1974, DE 19 DE DICIEMBRe. DEFINICIONES LEGALES}

La vigente Ley de Carreteras de 1974 (46) puede caracterizarse, entre otras notas peculiares, por su contenido definitorio jurídicoformal como contraste con la regulación anterior, en la que, como hemos visto, las categorizaciones formales no se podian hallar con facilidad.

Las definiciones legales de carácter objetivo se contraen a la delimitación - abstracción hecha de su sujeto titular- de las carreteras (47) y sus distintas clases. Las carreteras, que son el objeto en definitiva de esta regulación, se plantean desde un punto de vista positivo como el género vías de dominio y uso públicos proyectadas y construidas para la circulación de vehículos automóviles (48); en una delimitación negativa serán las vías públicas para circulación de automóviles que no sean vías urbanas -red interior de comunicaciones municipales (49) - ni caminos de servicio públicos o privados, que son a su vez vías constitutivas de elementos auxiliares - complementarios de las actividades específicas de sus titulares (50).

(46) Ley 51/1974, de 19 de diciembre.

(47) Ley de Carreteras (LC), artículo $10^{\circ}$, apartado $10^{\circ}$.

(48) Ley de Carreteras, artículo $10^{\circ}$, apartado $2 .^{\circ}$, y Reglamento General de Carreteras (RC), aprobado por Real Decreto 1.073/1977, de 8 de febrero, artículo $1 .^{\circ}$, apartado $20^{\circ}$.

(49) LC, artículo $30^{\circ}, 10^{\circ}$, apartado a); RC, artículo $7 .^{\circ}$, apartado a).

(50) LC, artículo $30^{\circ}, 10^{\circ}$, apartados b) y c), y $20^{\circ} ;$ y RC, artículo $70^{\circ}$, apartados a) y $c)$. 
Las distintas especies de carreteras que se singularizan en la Ley son las autopistas y las autovías. La Ley de Carreteras recoge literalmente la definición legal de autopistas de la Ley de Autopistas de 1972 (51), con lo que por vía de objetivización de la regulación toma carácter general lo que desde el año 1972 al 1974 tan sólo fue aplicable a las autopistas tipificadas subjetivamente por su titularidad estatal.

Se introduce, no obstante, un nuevo tipo legal —en las categorizaciones jurídicas formales- de carretera, y es el de la "autovía", que responde a una forma atenuada de autopista (52), ya que se trata de carreteras que teniendo algunos de los caracteres tipificados de las autopistas no los poseen todos ellos, siempre y cuando cóncurran al menos los de exclusiva circulación de automóviles y carezcan de acceso a ellas las carreteras colindantes.

Con ello, sin embargo, aunque en la Ley de Carreteras no se contemplan otros tipos de carreteras, no se agota el contenido genérico de las carreteras, por cuanto las autopistas y las autovías no son los únicos tipos de carreteras que existen, ya que no engloban todo el concepto matriz. Queda una categoría residual que, dada la formulación legal, se va a delimitar negativamente y que estará integrada por las carreteras no constitutivas de autopistas ni de autovías.

La categoría residual apuntada ha sido recogida por vía reglamentaria (53) con la denominación de carreteras convencionales, que se delimitan precisamente como "todas las que no tienen la consideración legal de autopistas o de autovías» (54).

Las delimitaciones subjetivas de la Ley de Carreteras se perfilan en torno al carácter de las carreteras -en cualquiera de sus tres tipos objetivos quedando fuera del término carretera los caminos de servicio- desde el punto de vista de su titularidad. Las carreteras, según ello, podrán ser estatales, provinciales y municipales, según sea el titular de las mismas el Estado, las Provincias o los Municipios o demás entidades locales (55). El criterio determinante

(51) LC, artículo $1 .^{\circ}$, apartado $3 .^{\circ}$, y Ley de Autopistas, artículo $1 .^{\circ}$, apartado 2. ; Reglamento de Carreteras, artículo $40^{\circ}$.

(52) LC, artículo $10^{\circ}$, apartado $4 .^{\circ}$; y RC, artículo $5 .^{\circ}$, apartado $1 . .^{\circ}$; ya se recogía a nivel reglamentario en la modificación del artículo $5 .^{\circ}$ del Código de la Circu. lación del Decreto de 26 de junio de 1969.

(53) RC, artículo $3 . \circ$

(54) RC, artículo $6 . \circ$

(55) LC, artículo $3 .^{\circ}$; y RC, artículo 9. 
de la caracterización de las carreteras con esta base subjetiva no es, sin embargo, tanto el de la titularidad en sí como el de la inclusión o no en determinado Plan de carreteras, bien sea el nacional para las estatales, el provincial para las provinciales, o su no inclusión en las anteriores, y la construcción por entrega a los Municipios para las municipales.

\section{Clasificación de las CaRreteras y distribución DE COMPETENCIAS}

Lo señalado en el punto anterior es manifestación del sistema rigorista y cerrado que la Ley de Carreteras establece en torno a su clasificación. La clasificación subjetiva de las carreteras es un punto importante en cuanto que resulta determinante de la titularidad de las mismas y con ello del ejercicio de las potestades competenciales que el ordenamiento atribuye a cada titular; la clasificación de una carretera da lugar además a la aplicación de un régimen jurídico específico en función del tipo en que quede incluida (56).

Toda carretera ha de pertenecer a una u otra entidad titular, con lo que se configura un sistema cerrado que se caracteriza porque la atribución de determinada carretera a determinado sujeto se produce en última instancia como consecuencia de su inclusión o no en unas u otros Planes de carreteras. El sistema se formaliza aún más por la aparición, por vía reglamentaria, de un catálogo de carreteras del que, en definitiva, van a resultar las caracterizaciones de éstas (57).

La Ley de Carreteras establece la existencia inexcusable de Planes de carreteras nacionales y provinciales y de carácter potestativo en el caso de los Municipios (58). La distribución de competencias, en cuanto a la aprobación de estos Planes, pueden resumirse así: el Plan nacional de carreteras se elabora por el Ministerio de Obras Públicas, se acuerda su remisión a Cortes por el Consejo de

(56) De la Vallina Velarde, J. L., «Marco jurídico-administrativo de las vías provinciales", en I Jornadas Nacionales de Estudio sobre las Vias Provinciales, vid. en páginas 304 y ss., acerca de la competencia provincial sobre vías públicas.

(57) RC, artículos 14 y 18.

(58) Artículos $8 .^{\circ}, 90^{\circ}$ y 10. 
Ministros y se aprueba por ley formal (59); el Plan provincial de carreteras se elabora por la Diputación Provincial y se aprueba por el Consejo de Ministros (60), y los Planes provinciales de carreteras, en el caso de que se quieran confeccionar, se elaboran por los Ayuntamientos y se aprueban por el Gobernador civil (61).

Es importante, pues, tener en cuenta que la titularidad de las carreteras está en función de su calificación formal e inclusión o no en uno u otro Plan de carreteras, lo que es tanto como dejar la calificación de las carreteras al órgano que corresponde la aprobación de cada Plan, si bien no hay que olvidar que el carácter de ley formal del Plan nacional es determinante de la delimitación negativa de las carreteras provinciales y municipales, en cuanto que sólo tendrán estas últimas calificaciones aquellas que no estén incluidas en el Plan nacional y, por tanto, no sean estatales.

Se configura, pues, la calificación subjetiva de las carreteras por un sistema cerrado y formalista que llega a dar auténtico valor constitutivo y esencial al documento formal del Plan, que, junto con el catálogo, determinan la caracterización subjetiva, y con ella, también el régimen jurídico, de cada carretera. Este sistema, además, se establece a través de una compleja formulación competencial que se concreta en que en ningún caso el ente titular aprueba el Plan de sus propias carreteras y en que la delimitación no resulta sólo de la pura inclusión de las carreteras en aquél, sino que se opera negativa y sucesivamente por exclusión de las carreteras atribuidas, respectivamente, al ente territorial de mayor ámbito del que se esté examinando en cada momento.

\section{LAS CARRETERAS Y AUTOPISTAS PROVINCIALES}

\section{A) Concepto}

Según lo expuesto, las carreteras provinciales pueden conceptuarse como vías de dominio y uso públicos proyectadas y construidas para la circulación de vehículos automóviles no incluidos en el Plan nacional de carreteras e incluidas en algún Plan provincial de carreteras, catalogadas como tales y de titularidad provincial.

(59) LC, artículos $4 .^{\circ}$ y $5 .^{\circ}$.

(60) LC, artículo 9.; y RC, art. 18.

(61) LC, artículo 10; y RC, artículo 19. 
Su encuadre como tales se produce a propuesta de la Diputación correspondiente y la decide el Consejo de Ministros. Todo ello en función del interés público provincial y sin que se les pueda dar este carácter a las carreteras incluidas en el Plan nacional de carreteras. Es clara la caracterización formal de las carreteras provinciales, ya que el único dato que se refiere a su función, interés, finalidad $u$ otras características es el vago y poco vinculante del interés público provincial; el resto de datos responde a puras cuestiones formales de encuadramiento, que además escapan a las competencias decisorias del que va a ser su ente titular.

Las autopistas provinciales serán un tipo más de carreteras provinciales, como lo pueden ser las autovías provinciales o las carreteras convencionales.

Para la existencia y calificación de una autopista provincial, sólo se requerirá que ésta se trate de una carretera que reúna los requisitos generales característicos de las autopistas y que se encuentre incluida en el Plan provincial de carreteras debidamente aprobado y, en consecuencia, debidamente catalogada como tal; la incidencia del interés público provincial en la calificación no afecta, a nuestro juicio, a la consideración jurídico-formal de determinado caso concreto ya calificado; el dato del interés provincial sólo será operante, de hecho, cuando se trate de incluir o no una carretera o autopista en la calificación de provincial o cuando se trate de modificar su calificación.

\section{B) Los tipos de carreteras provinciales por razón del peaje}

A la vista de lo expuesto sobre las definiciones legales acerca de las carreteras, resulta claro que las autopistas, autovías y demás carreteras que no tengan las características de aquéllas quedan incluidas en el contenido de la expresión carretera, sin adjetivaciones, y ello con independencia de la titularidad a que vengan referidas aquéllas.

La expresión carreteras provinciales, pues, engloba a las autopistas, autovías y demás carreteras (62) que no estén incluidas en el Plan nacional de carreteras y que se incluyan en un Plan provincial de carreteras y tengan interés público provincial. Las carre-

(62) El Reglamento de Carreteras las denomina carreteras convencionales, como ya se ha señalado. 
teras provinciales calificadas en estos términos son de titularidad provincial, lo que significa que el titular del dominio público que constituyen será la Diputación Provincial, que su régimen jurídico se integrará por la legislación general de carreteras y por las normas de Régimen local que les resultasen aplicables y que la competencia general sobre ellas vendrá atribuida a las Corporaciones provinciales.

Básicamente, las carreteras provinciales, y con ellas las autopistas, autovías y carreteras convencionales provinciales, pueden clasificarse en dos grandes grupos por razón del peaje: el primero engloba a las carreteras provinciales que carecen del peaje, y el segundo, aquellas cuya utilización conlleva peaje.

Las carreteras provinciales sin peaje constituyen el tipo más generalizado cuantitativamente de las carreteras provinciales; responden a una forma de explotación directa de las mismas por sus entes titulares y se caracterizan legalmente por la utilización gratuita por el usuario de las mismas y por constituirse en la regla general de la explotación de las carreteras provinciales, que en este punto asumen la misma normativa que las estatales y las municipales (63).

Las carreteras provinciales con peaje son, al contrario, mucho menos numerosas que las anteriores y se caracterizan por la posibilidad de ser explotadas tanto por la propia Corporación provincial como por los particulares (64), cuyas fórmulas y régimen jurídico estudiamos en el punto siguiente.

\section{C) El régimen jurídico específico de las carreteras provinciales de peaje}

Al desarrollar este punto nos referiremos solamente al régimen jurídico de las carreteras provinciales de peaje en cuanto a tales, es decir, que omitimos el examen de estas carreteras en lo que se refiere a su propia característica de tal carretera en cuanto es un régimen jurídico común a todas las carreteras provinciales, con independencia de que sean de peaje o no (65). Tratamos, pues, de las

(63) LC, artículo $27,2$. .

(64) LC, artículo $27,10^{\circ}$ y $20^{\circ}$.

(65) La articulación parcial de la Ley 41/1975, de Bases del Estatuto de Régimen local, operada por el Real Decreto 3.046/1977, de 6 de octubre, no altera sustancialmente el régimen jurídico de las carreteras provinciales de peaje, ę cuanto 
especialidades que el establecimiento de peaje puede suponer en punto al régimen jurídico de las carreteras; con tal propósito estudiamos separadamente las carreteras provinciales de peaje explotadas por las propias Diputaciones provinciales titulares de las mismas, de una parte parte, y de otra, las carreteras provinciales de peaje explotadas por los particulares.

\section{a) Las carreteras provinciales de peaje explotadas por sus entes titulares}

Este tipo de carretera se configura, como ya hemos apuntado, como una carretera provincial -en cualquiera de sus clases- por la característica de su explotación directa mediante peaje por la Diputación Provincial titular de la misma; como la misma Ley establece (66), se trata de un caso excepcional, siendo la regla general de la explotación directa el uso gratuito de la carretera.

La explotación directa por el propio ente titular de la carretera supone unas variaciones sobre el régimen jurídico fundamental general de las carreteras provinciales que se centran fundamentalmente en la construcción, financiación y la propia explotación de la carretera, variaciones éstas que estudiamos separadamente.

\section{a') Construcción y financiación}

La explotación directa de las carreteras provinciales de peaje por el propio ente titular de las mismas apenas si produce variaciones sobre el régimen general de las carreteras provinciales en cuanto a su construcción, ya que en principio el establecimiento del peaje no está vinculado a la construcción de la carretera; es decir, el establecimiento del peaje puede hacerse tanto sobre una carretera construida ya como decidirse acerca de una carretera aún inexistente, $y$, por tanto, no se hará efectivo hasta que ésta entre en uso.

En suma, el futuro establecimiento o no de un peaje como forma de explotación directa de la carretera no afecta al régimen ju-

que deja vigente el Reglamento de Contratación y el de Servicios de las Corporaciones locales, así como la Ley de Régimen local, en lo que no se opongan a dicha articulación, sin que ésta regule la cuestión que estudiamos.

(66) LC, artículo $27,2 .^{\circ}$ 
rídico de su construcción en general, șalvo en lo que pueda resultar de la incidencia de la financiación en su contrucción, y ello en el sentido de condicionante previo que la financiación de la carretera puede tener para su construcción o bien en el desarrollo del pago de las obras y con independencia de los fondos de financiación que en alguna medida no vengan referidos al peaje.

En todo caso, la construcción de una carretera provincial de peaje en régimen de explotación directa no difiere fúndamentalmente de la de una carretera provincial de explotación directa sin peaje. En este sentido regirá la legislación de Régimen local (67) por remisión expresa de la propia Ley de Carreteras (68).

Otro tanto ocurre con la financiación de las futuras carreteras provinciales de peaje explotadas directamente en cuanto que, según la propia Ley de Carreteras, solamente se variará el sistema general de financiación cuando se trate de carreteras en régimen de gestión indirecta o mixta (69). Sin embargo, el establecimiento de peaje en el sistema de gestión directa puede afectar a la financiación de las correspondientes carreteras, e incluso por esta vía a la construcción de la misma en cuanto al pago efectivo de las obras.

Lo anterior se puede producir por la aplicación de las normas peculiares de Haciendas locales acerca de la financiación de obras de nueva planta. La Ley de Carreteras establece que las provinciales se financiarán con cargo a sus propios créditos presupuestarios conforme a la legislación vigente (70), lo que significa que es por aplicación de las normas presupuestarias de Régimen local (71); las carreteras a construir son obras de nueva planta, lo que supone la necesidad de su financiación a través de un presupuesto extraordinario que puede recurrir al crédito para nivelar sus ingresos, crédito que puede amortizarse, junto con los intereses, afectando al pago los importes de los peajes percibidos por la explotación (72).

(67) Estas normas de Régimen local se integran principalmente por las correspondientes a obras y servicios provinciales (arts. 285 a 291 de la Ley de Régimen local y Reglamento de Servicios de las Corporaciones locales) y a la contratación provincial (arts. 307 a 318 de la Ley de Régimen local y Reglamento de Contratación de las Corporaciones locales), con las modificaciones operadas por el R. D. 3.046/1977.

(68) Artículo 20.

(69) Artículo $23,2$. , por remisión expresa del artículo 25, apartado $3 .{ }^{\circ}$.

(70) Artículo 25, 1.․

(71) Ley de Régimen local, artículos 694, 695 y 705, 2., apartado a).

(72) Ley de Carreteras, artículo 27, apartado $20^{\circ}$. 


\section{b') El carácter de servicio público}

La construcción y conservación de las carreteras provinciales, al igual que todas las competencias atribuidas a las Corporaciones provinciales, se califican por la Ley de Régimen local como servicios (73), calificación que se reitera al hablar de obras y servicios provinciales (74), si bien luego se conceptúan las obras provinciales como aquellas que se realizan para la ejecución de servicios de la competencia provincial (75). Es evidente, sin entrar en el examen de la noción de servicio público, que las calificaciones de la Ley de Régimen local han de referirse no tanto a la obra pública que es una carretera como a la actividad de construcción o explotación de la misma al calificarlas a aquéllas de servicio público (76).

En el mismo sentido se ha de entender la regulación de la Ley de Carreteras cuando se refiere a las formas de explotación de las carreteras estatales, ya que está aplicando, incluso expresamente (77), los sistemas de gestión de servicios previstos en la Ley de Contratos del Estado (78).

Así, pues, a los efectos formales de determinación del régimen jurídico aplicable, la explotación de las carreteras ha de inscribirse en el marco de la gestión de servicios basados en una obra pública, la propia carretera, y, por tanto, las concesiones que se otorguen habrán de reputarse concesiones de servicios y no de dominio público, como podría pensarse de la naturaleza del objeto de la misma y del sistema establecido tradicionalmente por nuestra legislación (79).

\section{c') Las formas de gestión directa}

Establecida la explotación de las carreteras en general y las provinciales en particular como una actividad calificable de servicio

(73) Artículo 243, apartado a).

(74) Artículo 285.

(75) Artículo 287.

(76) GOMEZ-FERRER MORANT, R., trata la cuestión a propósito de las autopistas del Estado en «En torno a la Ley de Autopistas de peaje», op. cit., págs. 331 y ss.

(77) Artículo 28.

(78) El artículo 30 prevé la explotación de carreteras estatales por gestión interesada, concierto y sociedad de economía mixta.

(79) Así, por ejemplo, la Ley de Obras públicas de 1877 vigente parcialmente. 
público - al menos formalmente-, serán aplicables a esta explotación los sistemas de gestión directa de servicios que a tal efecto se prevén en la normativa de Régimen local, y ello por remisión expresa de la Ley de Carreteras (80).

Las Diputaciones provinciales podrán, pues, explotar sus carreteras directamente por la propia Corporación - con o sin órgano especial - mediante una fundación pública del servicio o mediante una sociedad privada provincial (81), que son las formas típicas de gestión directa de servicios establecida por la normativa de Régimen local. La posibilidad de que la explotación directa de la carretera provincial de peaje se realice por persona jurídica pública o privada distinta a la de la propia Corporación provincial - como es el caso de la fundación pública del servicio o de la sociedad privada provincial- se infiere del propio concepto jurídico formal de la normativa de Régimen local, que entiende por gestión directa tanto la que realicen por sí mismas las Corporaciones como las que se verifiquen "por organismo exclusivamente dependiente de ella» (82).

\section{d') Tarifas de peaje}

Hay que distinguir dos supuestos -el de las carreteras provinciales financiadas total o parcialmente con fondos estatales y las financiadas con fondos sin participación del Estado- En el primer supuesto se establece que la aprobación de las tarifas se hará por el Gobierno (83), por lo que en este caso el peaje y su tarifa seguirán la condición tributaria que en el régimen estatal resulte, y ello en función de los convenios de financiación de la construcción que pudieran haberse establecido previamente. La calificación tributaria del peaje, dentro de la tradicional tripartición de los tributos en impuestos, contribuciones especiales y tasas, parece que debe ser la de tasa por prestación de servicios, lo que supone un beneficio especial para el usuario; sin embargo, el tema entra en la especialidad del Derecho financiero y tributario estatal y no res-

(80) Artículo 31.

(81) Reglamento de Servicios de las Corporaciones locales, aprobado por Decreto de 17 de junio de 1955, artículos 67 y siguientes.

(82) Reglamento de Servicios de las Corporaciones locales, artículo 41.

(83) Ley de Carreteras, artículo 27, apartado 2.: 
ponde al propósito de este trabajo, por lo que nos limitamos a plantearlo en este caso especial sin insistir más en él (84).

El segundo supuesto es el que se plantea respecto del peaje y las tarifas del mismo cuando la carretera provincial se financia con fondos no estatales. En este supuesto hay remisión expresa a la fórmula de aprobación de tarifas establecida por la legislación de Régimen local (85), que en este caso se integra principalmente por la Ley de Régimen local, el Reglamento de Servicios de las Corporaciones locales y el Reglamento de Haciendas locales.

El carácter de tasa o precio del peaje en materia de Régimen local varía en función de la forma de gestión del servicio que se adopta. En el caso de la gestión directa, con o sin órgano especial o mediante fundación pública del servicio, es incontestable el carácter de tasa del peaje (86); en el caso de gestión directa a través de sociedad privada municipal, el peaje deberá tener carácter de precio, pues así se establece con carácter general, sin que las excepciones de servicios monopolizados o de recepción obligatoria parezcan aplicables, en cuanto que, aunque la explotación de una carretera es un monopolio de hecho, desde un punto de vista jurídico formal no es un servicio monopolizado por aplicación de los sistemas de provincialización ni declarado de obligatoria recepción (87).

Corresponderá aprobar las tarifas de peaje a la propia Corpo. ración provincial titular de la carretera, sin que en principio se aprecie necesidad de intervención de la Administración del Estado, por cuanto no se trata de un servicio de carácter industrial o mercantil (88), y sin que en la determinación de su cuantía se tenga que reflejar el costo de la explotación, ya que el peaje puede resultar superior, inferior o igual a dichos costes (89).

Si se califica el peaje como tasa será de aplicación al régimen

(84) Vid. GaRcta dE ENTERR1a, E., «Sobre la naturaleza de la tasa y las tarifas de los servicios públicos", en Revista de Administración Pública, núm. 12, 1960, página 259; ARIN̄o ORTIZ, Gaspar, "Las tarifas de los servicios públicos», op. cit., páginas 101 y ss. y notas 1 a 10 . También Rodrfguez Moro, N., «Naturaleza del precio que pagan los usuarios de un servicio de aguas municipalizado con monopolio», en REVISTA DE Estudios DE LA VIDA LoCAL núm. 170, 1971, páginas 327 y ss.

(85) Ley de Carreteras, artículo 27 , apartado $2 .^{\circ}$ in fine.

(86) Artículo 155, apartado $10^{\circ}$, del Reglamento de Servicios de las Corporaciones locales.

(87). Artículo 155, apartados $2 .^{\circ}$ y $30^{\circ}$, del Reglamento de Servicios de las Corporaciones locales.

(88) Artículo 148 del Reglamento de Servicios de las Corporaciones locales.

(89) Artículo 149 del Reglamento de Servicios de las Corporaciones locales. 
que para los derechos y tasas como exacciones provinciales establece la Ley de Régimen local y el Reglamento de Haciendas locales, quedando expresamente fuera de esta regulación los peajes en concepto de precios o retribución del servicio (90). El peaje en concepto de tasa requerirá la formación y aprobación de la correspondiente ordenanza fiscal (91) al tiempo que se acuerda la imposición.

\section{b) Las carreteras provinciales de peaje explotadas por particulares}

El caso de carreteras provinciales de peaje explotadas por los particulares se traduce por aplicación de las normas de Régimen local, principalmente en formas de gestión indirecta de servicios y, en menor medida, por el sistema de gestión mixta (92), que estudiamos separadamente.

Como es sabido, las formas de gestión indirecta de servicios locales son la concesión, el arrendamiento y el concierto (93): De estas formas de gestión sólo son aplicables a la explotación de las carreteras provinciales la concesión y el arrendamiento. El concierto, por su propia naturaleza, no parece ser adecuado como forma de gestión de la explotación de una carretera, porque el uso concertado por la Corporación de los servicios que otros entes - públicos o privados- puedan tener establecidos (94), no resulta posible dados los caracteres de demanialidad y titularidad pública del objeto básico de la gestión - las carreteras y su explotación-, que no parecen encajar en el planteamiento de este tipo de gestión.

\section{a') La concesión}

La fórmula clásica de gestión de servicios públicos y de construcción y aprovechamiento de obras públicas con cargo a sus propios rendimientos a través de los particulares es la concesión administrativa, y en este caso es la figura más adecuada, a nuestro

(90) Artículo $80^{\circ}$ del Reglamento de Haciendas locales, aprobado por Decreto de 4 de agosto de 1952.

(91) Artículo 127 y siguientes del Reglamento de Haciendas locales.

(92) Ley de Carreteras, artículo 31 en relación con el Reglamento de Servicios de las Corporaciones locales, artículos 102 y 113 y siguientes.

(93) Reglamento de Servicios de las Corporaciones locales, artículo 113.

(94) Reglamento de Servicios de las Corporaciones locales, artículo 143. 
juicio, para la construcción y explotación de las carreteras provinciales de peaje.

Dado el carácter complejo de esta figura que pretendemos examinar en la perspectiva de las carreteras provinciales de peaje, y teniendo en cuenta que su régimen jurídico es aplicable por remisión, como veremos, a la figura del arrendamiento, estudiaremos los puntos de más interés en la concesión de carreteras provinciales en los aspectos señalados.

\section{a") El objeto de la concesión}

Aunque esta concesión regulada por la legislación de Régimen local se plantea básicamente como una concesión de servicio - a diferencia del origen de esta figura como concesión de dominio y su planteamiento legislativo en la Ley de Obras públicas-, la concesión de las carreteras provinciales de peaje se puede establecer tanto sobre la gestión de la explotación en sí como sobre esa explotación y la construcción de la obra.

La fórmula de concesión de carretera provincial de peaje con ejecución de la obra -en especial las autopistas provinciales de peaje- será la más viable en la realidad, por cuanto las otras fórmulas de gestión, aunque posibles jurídicamente, no responden plenamente a la problemática de estos supuestos.

Las explotaciones directa e indirecta con obra previamente existente no justifican la imposición del peaje - salvo para amortizaciones de créditos- en cuanto que el costo del servicio que está primordialmente integrado por la construcción de la carretera, por el costo de la obra en sí, en este caso ya se encuentra invertido en su mayor parte al comenzar a explotar la carretera; por tanto, el peaje resulta un ingreso tardío y aleatorio en su cuantía, lo que no permite una correcta financiación y pago de la obra.

Por el contrario, la explotación de las carreteras provinciales de peaje por particulares mediante concesión que incluya, además de la gestión, la construcción de la obra sí supone una ventaja palpable para la Corporación concedente porque — siguiendo el clásico principio de la concesión - se construye la obra y se presta el servicio todo ello con titularidad provincial, sin tener que invertir -al menos en su totalidad- en el costo de la obra fondos provinciales, ya que es mediante el peaje como el concesionario se resarce del 
costo de la obra, asumiendo éste el posible riesgo que la aleatoriedad de los ingresos del peaje conlleva.

Será, pues, lógico pensar como más adecuado a la construcción y explotación de carreteras provinciales de peaje el sistema de gestión indirecta mediante concesión de servicios que lleve incluida la construcción de la obra.

\section{b") Competencia para el otorgamiento de la concesión $y$ titularidad del servicio}

Corresponde exclusivamente a la Diputación Provincial la concesión de la explotación de carreteras provinciales, en cuanto a tales, por aplicación conjunta de la Ley de Carreteras y las normas peculiares de la concesión en materia de Régimen local (95).

La titularidad de la carretera y de la explotación en cuanto a actividad de servicio queda en todo caso, y ello en la más pura línea de la actividad concesional, en la Diputación Provincial competente (96). Ello tiene como consecuencia, de un lado, la atribución de la facultad de fiscalización de la explotación con carácter irrenunciable - y como causa de nulidad concesional - al ente titular (97) y, de otro lado, la posible atribución de poderes exorbitantes al concesionario con carácter delegado del concedente (98).

La iniciativa de la concesión de una carretera puede provenir tanto de la propia Corporación provincial concedente como de cualquier particular. La iniciativa de la Corporación supone que ésta tiene perfectamente delimitado el objeto de la misma y lo saca a licitación pública para la adjudicación de la concesión.

El supuesto de iniciativa particular se sustancia en una doble fase. La primera o inicial que consiste precisamente en la delimitación exacta de lo que va a ser el contenido de la concesión, incluso la redacción del proyecto de la carretera que la Corporación provincial ha de asumir, y la segunda que se centra en la licita-

(95) Ley de Carreteras, artículo 31, y Reglamento de Servicios de las Corporaciones locales, artículos 14 , ap. $3 .^{\circ}$, y 124 en relación con el 243 , a), de la Ley de Régimen local.

(96) Reglamento de Servicios de las Corporaciones locales, artículo 126.

(97) Reglamento de Servicios de las Corporaciones locales, artículo 116, apartado $10^{\circ}$.

(98) Reglamento de Servicios de las Corporaciones locales, artículo 126, apartado $3 .^{\circ}$. 
ción de la concesión en términos análogos a los de la primera señalada (99).

Los derechos y deberes dimanantes de la relación concesional se explicitan en la propia legislación de Régimen local bajo la fórmula de potestades de la Administración y obligaciones del concesionario (100).

\section{b') El arrendamiento}

Es figura de gestión indirecta a través de particulares arrendatarios de un servicio a partir de instalaciones existentes y de titularidad del ente concedente (101).

El arrendamiento de carreteras provinciales de peaje es, pues, una forma de gestión que excluye la construcción de la carretera. El objeto de esta forma de gestión queda así reducido a la explotación de la carretera, cuya existencia previa al arrendamiento es consustancial a la propia naturaleza de aquél.

Se trata de una forma de gestión de la explotación de carreteras provinciales de peaje análoga a la que podría resultar de la concesión de aquélla, sin que comporte la construcción de la misma. Esta idea es la que preside la propia regulación del arrendamiento, pues se establece que será aplicable la regulación sobre concesión administrativa en cuanto no resulte incompatible con la propia figura del arrendamiento (102).

Es de destacar, sin embargo, el carácter de precio que por aplicación de la regulación sobre tarifas de los servicios locales hay que predicar del peaje en el caso del arrendamiento, y ello en función de la consideración privatista que se da a esta forma de gestión (103). En consecuencia, no le serán de aplicación los preceptos relativos a las tasas en los casos que ya hemos expuesto anteriormente.

(99) Reglamento de Servicios de las Corporaciones locales, artículos 117, 118, $119,120,121$ y 122.

(100) Reglamento de Servicios de las Corporaciones locales, artículos 127 y 128 , respectivamente.

(101) Reglamento de Servicios de las Corporaciones locales, artículo 138.

(102) Reglamento de Servicios de las Corporaciones locales, artículo 140, apartado $20^{\circ}$.

(103) Reglamento de Servicios de las Corporaciones locales, artículo 155, apartado $2 .{ }^{\circ}$. 


\section{c') La gestión por empresa mixta}

La gestión por empresa mixta de la explotación de carreteras provinciales de peaje es una de las posibles fórmulas de gestión de aquéllas en cuanto que resulta ser un sistema de los previstos en la legislación local para la prestación de servicios, y ello por aplicación de la normativa remisoria de la legislación de carreteras ya señalada (104).

La gestión por empresa mixta es un modo de gestión intermedio entre la directa y la indirecta en cuanto que participa de ambos más que en su forma específica en el reparto del riesgo de la explotación y el control de la gestión. Lo típico de la gestión de la empresa mixta es la participación de capital privado y público en la inversión que requiera la prestación del servicio, participación conjunta ésta que se instrumenta a través de la creación de una sociedad privada por la forma y mixta por razón de los fondos que en ella se engloben.

De esta manera nos encontramos con una forma de explotación que, sin ser estrictamente privada - parte de los fondos, y con éstos, parte del control, son de origen público-, no es en modo alguno un sistema de explotación directa, y ello porque la sociedad de economía mixta no depende exclusivamente del ente local titular, en cuanto que éste no asume totalmente el riesgo de la gestión de la explotación, pero tampoco financia totalmente dicha explotación.

Es, pues, un sistema que cae dentro de la categoría de explotación de las carreteras provinciales de peaje por particulares, pero sin constituir un sistema indirecto, y además sin que quepa calificarlo como sistema de explotación directa. La personalidad de la sociedad de economía mixta que gestione la explotación de carreteras provinciales será de carácter privado, como se desprende de la existencia de acciones si se funda ex nóvo o la suscripción de las existentes si se adquieren de empresa ya constituida (105).

Estas características hacen pensar en la existencia de una personalidad privada en las empresas mixtas, aunque habrán de exa-

(104) Ley de Carreteras, artículo 31.

(105) Reglamento de Servicios de las Corporaciones locales, artículo 104, apartado $20^{\circ}$ 
minarse los estatutos de éstas para la correcta determinación jurídico-formal del carácter de su personalidad.

En cuanto a las tarifas, señalaremos que nada se precisa en la normativa de Régimen local al respecto, salvo la concreción de que si el servicio se presta por concesión a empresa mixta, la tarifa tendrá carácter de tasa. Sin embargo, ello no predetermina suficientemente el carácter de tasa de las percepciones de las empresas mixtas, en cuanto que la prescripción señalada lo es en función de la concesión y con independencia del carácter privado o mixto del concesionario (106).

Hay que tener en cuenta que el sistema de gestión mixta, más que una categoría formal de un modo de gestión, es una fórmula de financiación de la personalidad prestadora del servicio. A los efectos de la calificación del peaje como tasa o precio de servicio habrá que estar, más que al porcentaje de participación de capital público o privado, a la naturaleza de la personalidad de la sociedad mixta y al régimen jurídico a que la someten sus estatutos.

Estimando como más adecuado el planteamiento de las empresas mixtas, la personalidad privada de las mismas y su sometimiento a las normas de Derecho privado, el carácter que se ha de predicar del peaje ha de ser el de precio, y ello por aplicación de las fórmulas normativas que establecen que cuando el servicio se preste con arreglo al Derecho privado, las tarifas tendrán el carácter de precio (107).

\section{D) Financiación y tarifas}

La financiación de la carretera provincial, cuando se concede la explotación, y la construcción, se harán precisamente con cargo al capital de la sociedad concesionaria, los recursos propios o ajenos que éstas movilicen, además de las subvenciones que otorgue la propia Diputación Provincial titular (108).

En cuanto a la tarifa de peaje correspondiente, hay que señalar

(106) Reglamento de Servicios de las Corporaciones locales, artículo 155, apartado $10^{\circ}$

(107) Reglamento de Servicios de las Corporaciones locales, artículo 155, apartado $20^{\circ}$

(108) Ley de Carreteras, artículos 25 , apartado $3 .^{\circ}$ y 23 , apartado $2 .^{\circ}$, por remision del anterior. 
que ésta es por principio revisable (109) y que entra en calificación de parte de la retribución económica del concesionario.

En cuanto al carácter de tasa o precio del peaje, nos remitimos a lo dicho sobre el tema anteriormente, si bien hay que precisar, sobre lo anterior, que la retribución del concesionario se contrae reglamentariamente al percibo de contribuciones especiales, tasas de los usuarios y subvenciones (110), por lo que en este punto cabe pensar en la calificación legal de tasa por el peaje de la tarifa de explotación de la carretera provincial concedida. A mayor abundamiento, las tarifas de los servicios prestados por concesión a particulares se consideran también como tasa en la propia regulación reglamentaria (111).

\section{CONCLUSIONES}

1. La regulación previa a la Ley de Carreteras de 1974 responde a una óptica estatal en la plasmación del régimen jurídico de las carreteras en general. La regulación citada descansa fundamentalmente en la vieja Ley de Carreteras de 1877, remozada por la Ley de Carreteras en régimen de concesión de 1960 y la Ley de Autopistas de 1972, lo que constituye un bloque legislativo de aplicación preferente a las carreteras estatales, ya que para las provinciales sigue aplicándose la primitiva ordenación de 1877.

2. ${ }^{2} \quad$ Hasta la Ley de Carreteras de 1974, el establecimiento de peaje y la concesión de carreteras provinciales ha de referirse a la Ley de Carreteras y a la 'de Obras públicas, ambas de 1877, sin que - como se ha dicho- los avances legislativos que suponen las leyes de 1960 y 1972 de Carreteras en régimen de concesión y Autopistas sean aplicables a las Corporaciones locales, como tampoco lo eran sus normas privativas de gestión de servicios; de aquí la óptica estatal de la regulación del tema en este período.

3. ${ }^{\text {L }}$ La regulación anterior a la Ley de Carreteras adolece de una indefinición en el uso de los términos y la delimitación de sus contenidos, que se palía con la aparición, en primer lugar y por vía de actos singulares, de las primeras concesiones concretas de auto-

(109) Reglamento de Servicios de las Corporaciones locales, artículos 116, apartado $3.0^{\circ} ; 126,2$, apartado b), y 127, 2, apartado B).

(110) Reglamento de Servicios de las Corporaciones locales, artículo 129.

(111) Reglamento de Servicios de las Corporaciones locales, artículo 155, apartado $10^{\circ}$ 
pistas de peaje del Estado, y en segundo lugar, por la mencionada Ley de Carreteras en régimen de concesión, y por último, por la Ley de Autopistas. Es de destacar, sin embargo, que este proceso evolutivo en la categorización jurídico-formal de los conceptos conexos con la carretera no afecta a las Corporaciones locales ni, por tanto, a las posibles carreteras y autopistas provinciales de peaje, cuyo régimen jurídico sigue anclado en la normativa de 1877 hasta la Ley de Carreteras de 1974.

4. ${ }^{\mathrm{a}} \quad$ La Ley de Carreteras de 1974 establece un sistema unitario de la regulación de las carreteras, con su dependencia de sus titulares, que se caracteriza por su contenido definitorio, y categorización de modo cerrado y unitario a la vez de las realidades de la figura de la carretera.

5. ${ }^{\text {a }}$ Como consecuencia del sistema unitario establecido por la Ley de Carreteras, las carreteras provinciales - y también las municipales - reciben un trato legislativo análogo al de las estatales en una perspectiva genérica de la regulación. La calificación de una carretera como estatal, provincial o local responde a criterios formalistas y de encuadramiento en unos y otros Planes de carreteras.

6. ${ }^{\mathrm{a}} \quad$ La explotación de las carreteras se concibe, a efectos del sistema a seguir para ello, como una actividad de servicio público, lo que abre paso a la regulación del conjunto por las normas genéricas correspondientes. Lo anterior significa que en la materia rigen los ordenamientos estatal y local en función del tipo y titular de la carretera. En el caso de carreteras del Estado, regirán las formas del contrato de gestión de servicios de la Ley de Contratos del Estado, y en materia de carreteras provinciales - y municipales-, la de Régimen local y Reglamentos de Servicios y Contratación de las Corporaciones locales.

7. ${ }^{\mathrm{a}}$ Los sistemas de explotación de las carreteras provinciales y del Estado de peaje son sensiblemente parecidos en el fondo, aunque varíe la normativa de la que provienen, lo que es consecuencia del fenómeno experimental que se observa en la legislación de Régimen local respecto de la estatal, que recoge casi siempre en sus disposiciones posteriores las prescripciones que han resultado positivas en el campo de lo local, mejorándolas normalmente.

8. ${ }^{a} \quad$ Las formas de gestión de la explotación de carreteras provinciales de peaje no varían sustancialmente de las formas genéricas de prestación de servicios de las Corporaciones locales. En principio, y con las debidas adaptaciones, se pueden utilizar para 
esta explotación cualquiera de los modos de gestión de servicios reconocidos a las Corporaciones provinciales por su propia normativa, salvo el de concierto, que por su naturaleza no resulta viable.

9. ${ }^{2}$ De las posibles formas de gestión de la explotación de las carreteras provinciales de peaje, estimamos parece la más adecuada la de concesión de la explotación y la construcción de la obra, por cuanto permite la construcción de la carretera sin, o con menor, inversión de fondos públicos y afectar la retribución del concesionario -el peaje- a la amortización de la propia obra, con mayor holgura económica incluso que si la construyese y explotase directamente la propia Corporación titular, y sin que el hecho de la concesión minore sensiblemente sus poderes y potestades sobre la carretera.

10. El peaje, a tenor de la legislación expuesta, requiere de una tarifa que se rige por la normativa de las Corporaciones locales, si no hay invertidos en la carretera fondos estatales. Esta tarifa, y con ella los tipos de peaje que contienen, tendrá carácter de tasa o de precio del servicio en función del régimen de gestión que se adopte.

Estimamos, sin embargo, que convendría el establecimiento de un criterio unitario al respecto que entendemos debe consistir en la consideración del peaje como una tasa, y ello porque gira sobre el aprovechamiento de un bien de dominio y uso públicos y responde perfectamente a la idea de tasa como pago en concepto de tributo o exacción repercutible en el directamente beneficiado por el uso de la carretera. En esta perspectiva se podría incluso fundar la regulación de Régimen local expuesta, entendiendo que se trata de un servicio que se presta con carácter monopolístico de hecho, aunque no medie provincialización con monopolio formalmente, lo que atraería cualquier consideración del peaje como precio de la prestación a la categoría tributaria de tasa provincial. 